\title{
Tecnologías de la Información Geográfica para todos los niveles educativos y socioeconómicos, SIG gratuitos vs SIG no gratuitos, aplicándolos al riesgo de procesos de remoción en masa, alcaldía Álvaro Obregón, Ciudad de México, México
}

\author{
Geographic Information Technologies for all \\ educational and socioeconomic levels, free GIS vs. \\ non-free GIS, applying them to the risk of mass removal \\ processes, Álvaro Obregón, Mexico City, Mexico
}

Oscar Daniel Rivera González*

Fecha de recibido: 11 de noviembre de 2019

Fecha de aceptado: 03 de junio de 2020

\begin{abstract}
Resumen
El motivo de realizar el siguiente trabajo de investigación, es demostrar que las personas de distintos niveles educativos y socioeconómicos, puede aprender y utilizar diversas Tecnologías de la Información Geográfica, así mismo poder utilizar este material didáctico-digital para la enseñanza de la geografía y cartografía en general en el mundo, como ejemplo de utilización real de estas tecnologías, se estudiarán los riesgos y amenazas en la alcaldía Álvaro Obregón de la Ciudad de
\end{abstract}

* Maestro en Urbanismo, Universidad Nacional Autónoma de México (UNAM), México, correo electrónico: oscardanieldanyboy@hotmail.com 
México, logrando este aprendizaje en educación media, superior y posgrado para compartirlo como caso de éxito, con base en la aplicación real de Sistemas de Información Geográfica (SIG) gratuitos, así como demostrar que tienen la misma efectividad en el trabajo de campo que los SIG no gratuitos, y que además, hasta cierto punto estos últimos limitan el aprender y conocer de tecnologías útiles para los estudiantes universitarios de cualquier parte del mundo y estrato social, como en el caso personal con la oportunidad de utilizar ambos, de allí, mi evaluación y crítica.

México cuenta con poca información, atención, gestión y coordinación, por parte de las autoridades de la alcaldía, estatales o federales, sobre la presencia de asentamientos humanos irregulares en zonas urbanas, y en los parámetros del sector norte de la alcaldía Álvaro Obregón, se observa un alto grado de vulnerabilidad física y nivel de marginación de sus habitantes, situados en laderas, cauces de ríos o barrancas, derivados de la geomorfología del lugar; expuestos a un peligro constante por su pronunciado grado de inclinación, por lo que al ocurrir algún deslizamiento, arrastra o acarrea la cimentación de las construcciones y lo que tenga a su paso, más aún en temporada de lluvias y en movimientos telúricos, lo que ocasiona pérdidas humanas, ambientales y económicas.

Por otra parte, esto da como resultado un deterioro medioambiental en torno al ecosistema que originalmente había, y que arbitrariamente se ha modificado con el paso de los años, con una desarticulada urbanización, ya que al realizarse este tipo de construcciones y edificaciones en zonas no aptas para su habitabilidad, por las problemáticas antes mencionadas, elimina o reemplaza la cobertura vegetal del suelo, viéndose modificado por el grado de cimentación que promueve la nula filtración del agua pluvial y por la compactación del mismo debido a la utilización de materiales para construcción.

Algo de suma importancia es, que las personas que habitan estas zonas rellenan o rellenaron pequeñas cavidades o minas con material de cascajo, residuos sólidos - basura para la nivelación del suelo, lo cual solo incrementa y trae graves consecuencias, haciéndolo aún más inestable.

Por lo anterior, los SIG gratuitos ayudan evidentemente a la gestión, coordinación, evaluación y toma de decisiones de la problemática, evitando pérdidas humanas por este tipo de acontecimientos geomorfológicos, queda claro que su uso puede ser hecho por cualquier persona, sin excusa ni pretexto de limitación.

Palabras clave: SIG (Sistemas de Información Geográfica), Tecnologías de la Información Geográfica, didáctico-digital, niveles educativos, niveles socioeconómicos, gratuitos, no gratuitos, vulnerabilidad y remoción en masa. 


\section{Abstract}

The reason for carrying out the following research work is to demonstrate that people of different educational and socioeconomic levels can learn and use different Geographic Information Technologies, as well as to be able to use this didactic-digital material for the teaching of cartography in general. The world, as an example of real use of these technologies, will be studied in this work, the risks and threats in the alcaldía Álvaro Obregón in Mexico City, achieving this learning in Middle, Higher and Postgraduate Education in the Mexican case and take it as an example to Latin America, based on the actual application of Free Geographic Information Systems (GIS), as well as demonstrating that they have the same effectiveness in fieldwork as non-free GIS, and that, to a certain extent, these The latter limit the learning and knowledge of useful technologies for university students anywhere in The world and social stratum, as a server, which has had the opportunity to use both, free and not free, hence my evaluation and criticism.

Mexico has little information, attention, management and coordination, by the authorities of the Mayor's Office, State or Federal, on the presence of irregular human settlements in urban areas, in the parameters of the northern area of the Álvaro Obregón town hall, in where there is some degree of physical vulnerability and high level of marginalization by the families that inhabit these areas, located on slopes, river beds and / or ravines, derived from the geomorphology of the place; and that they are a constant danger due to their pronounced degree of inclination, so that when this landslide occurs, it drags or carries the foundations of the constructions and what is in its way, especially in the rainy season and / or earthquakes, which causes human, environmental and economic losses.

On the other hand, this results in an environmental deterioration around the ecosystem that was originally found, and that was arbitrarily modified over the years, with this disjointed urbanization, since when these types of constructions and buildings are carried out in areas not suitable for habitability, for the aforementioned problems, it eliminates or replaces the vegetal cover of the soil, seeing itself modified by the grade of foundations, which promotes the null filtration of rainwater by the compaction of it, due to the use of materials for building.

Something of utmost importance is that people who inhabit these areas with some degree of vulnerability, fill or fill in some way small cavities or mines with gravel material, solid waste or garbage for leveling the soil, which only increases and brings serious consequences, making it even more unstable.

Therefore, the free GIS obviously help the management, coordination, evaluation and decision making of the problem, avoiding human losses due to this type of geomorphological events, it is clear that the use of GIS can be used by any person, without excuse or pretext of limitation. 
Key words: GIS (Geographic Information Systems), Geographic Information Technologies, didactic-digital, educational levels, socio-economic levels, free, not free, vulnerability and mass removal.

\section{Resumo}

A razão para a realização da presente pesquisa é demonstrar que pessoas de diferentes níveis educacionais e socioeconômicos, pode aprender e usar várias tecnologias de Informação Geográfica, a usar também este digital de ensino para cartografia de ensino em material em geral o mundo como um exemplo de uso real dessas tecnologias serão estudados neste trabalho, riscos e ameaças do prefeito Alvaro Obregon na Cidade do México, México, atingir essa aprendizagem no Media Education, Superior e Pós-Graduação, no caso mexicano e tomar como exemplo para a América Latina, com base na aplicação real de Sistemas de Informação livre geográfica (SIG) e demonstrar que possuem a mesma eficácia que o GIS não é livre trabalho de campo, e também, em certa medida, estes último limite aprender e conhecer de tecnologias úteis para estudantes universitários em qualquer lugar I mundo e estratos sociais, como um servidor, que teve a oportunidade de usar tanto o, portanto, a minha avaliação e crítica livre e não livre.

O México tem pouca informação, atenção, gestão e coordenação por parte das autoridades do Mayor, estadual ou federal, com a presença de assentamentos humanos irregulares em áreas urbanas, os parâmetros do norte de prefeito Alvaro Obregon em onde algum grau de vulnerabilidade física e marginalização alto nível observado por famílias que vivem nessas áreas localizadas em encostas, leitos de rios e / ou canyons, derivados lugar geomorfologia; e são um perigo constante para o seu grau pronunciado de inclinação, para que ocorra esse deslizamento, arrasta ou transporta as fundações de edifícios e que tem o seu caminho, especialmente na época e / ou terremotos chuvoso, causando perdas humanas, ambientais e econômicos.

Além disso, isso resulta em degradação ambiental em todo o ecossistema que era originalmente, e arbitrariamente mudou ao longo dos anos, com esta urbanização desarticulada, e que tais construções e edifícios realizadas em áreas não adequado para a habitação, para o problema acima, remover ou substituir a tampa de solo, vendo esta modificada pelo grau de fundação, o que promove a água da chuva filtração nula através da compressão dos resíduos, devido ao uso de materiais construção.

Algo de suma importância é que as pessoas que habitam nessas áreas com algum grau de vulnerabilidade preenchem ou preenchem de alguma forma pequenas cavidades ou minas com material de cascalho, resíduos sólidos ou lixo para nivelar o solo, o que só aumenta e traz sérios consequências, tornando ainda mais instável. 
Portanto, o SIG livre obviamente ajuda a gestão, coordenação, avaliação e tomada de decisão do problema, evitando perdas humanas devido a este tipo de eventos geomorfológicos, é claro que o uso do SIG pode ser utilizado por qualquer pessoa, sem desculpa ou pretexto de limitação.

Palavras-chave: SIG (Sistemas de Informação Geográfica), Tecnologias de Informação Geográfica, didático-digital, níveis educacionais, níveis socioeconômicos, livre, não livre, vulnerabilidade e remoção de massa.

\section{Objetivo general}

Analizar y evidenciar que la aplicabilidad de los SIG gratuitos vs SIG no gratuitos en modelos y mapas vectoriales, pueden alcanzar diversos objetivos de enseñanza y aplicabilidad en distintos niveles escolares y socioeconómicos.

\section{Objetivos particulares}

1. Estudiar y demostrar la aplicabilidad de los SIG gratuitos vs SIG no gratuitos, demostrando la efectividad de las herramientas que se tienen en la aplicación real de procesos de prevención, atención, corrección o reparación del daño, en cuanto a problemáticas y vulnerabilidad de asentamientos humanos marginados en zonas de peligro, derivadas de procesos de remoción en masa y su afectación a la infraestructura urbana, así como en sus viviendas.

2. Encontrar y demostrar que la aplicabilidad de modelos 3D con extensiones de archivos tipo raster (TIFF, GEOTIFF, BIL, BMP, etc.), y modelos 2D con visualización 3D para un mejor entendimiento de SIG gratuitos, pueden aminorar o desaparecer las problemáticas ambientales que se relacionen con procesos de prevención, corrección o reparación del daño, y la vulnerabilidad de asentamientos humanos, en zonas de peligro derivadas de procesos de remoción en masa y afectación a viviendas en zonas urbanas marginadas.

3. Comprender y revelar que la utilización de SIG no gratuitos, es solo apostar a un gasto mayor, perdiendo recursos económicos con el pago de licencias de los mismos, los cuales podrían ser destinados a otras causas con la utilización de SIG gratuitos, a los cuales se les deben dar una mayor difusión.

\section{Hipótesis}

Los SIG de código gratuito dan la misma información de calidad que los SIG no gratuitos en el aprendizaje escolar de cualquier estrato social y nivel escolar. En cuanto a la posible gestión del riesgos y evitar la pérdida de vidas humanas originadas por acontecimientos naturales, y en cuanto a procesos de remoción en 
masa con posibles soluciones a las autoridades encargadas para la evaluación del daño y riesgo, como es el caso de la alcaldía Álvaro Obregón, en cuanto a protección civil, así como los que generan las instancias gubernamentales como la Procuraduría Ambiental y del Ordenamiento Territorial del Distrito Federal (PAOT, 2010), la Secretaría de Desarrollo Urbano y Vivienda (SEDUVI, 2011), el Centro Nacional de Prevención de Desastres (CENAPRED) y el Servicio Geológico Mexicano (SGM), entre otras, para implementar procesos de gestión del riesgo y la prevención y atención en caso de corrección o reparación del daño relacionado a problemáticas y vulnerabilidad de asentamientos humanos sobre zonas inundables, así como al peligro de procesos de remoción en masa a lo largo de toda la demarcación, que dan como resultado serias afectaciones a la infraestructura urbana y de vivienda en colonias altamente marginadas e inclusive posibles muertes de los habitantes.

Por otra parte, afectaciones a lo largo de la demarcación al permitir la construcción en zonas altamente vulnerables y de reserva natural; así como el incremento en el número de niveles en las construcciones ya existentes, agravan esta problemática especialmente en temporada de lluvias o en episodios de movimientos sísmicos.

\section{Metodología del estudio con variables cualitativas y/o cuantitativas utilizadas}

El trabajo de investigación consistió en la ubicación, análisis, recopilación, búsqueda bibliográfica, hemerográfica, periodística y cartográfica del área de estudio; además del trabajo de campo cualitativo y cuantitativo, imágenes satelitales, sobrexposición de mapas vectoriales en 2D y 3D, herramientas de geoprocesamiento, así como trabajar con bases de datos geográficos (espaciales) y no geográficos (atributos), elaboración de nueva cartografía; todo esto evaluado y procesado con Software QGIS y GvSIG, SIG gratuitos, mismos que se pueden descargar en línea sin costo, y generación de información nueva con base en entrevistas, encuestas y puntos levantados con Sistema de Posicionamiento Global (GPS).

Además de lo anterior, la aplicación de procesamiento de imágenes raster, análisis de información geográfica vectorial, fotointerpretación, obtención de datos de las principales instituciones proveedoras de dicha información en México, como La Comisión Nacional para el Conocimiento y Uso de la Biodiversidad (CONABIO), Instituto Nacional de Estadística y Geografía (INEGI), Centro Nacional de Prevención de Desastres (CENAPRED), Comisión Nacional de Áreas Naturales Protegidas (ConanP), Secretaría de Medio Ambiente (SEDEMA), Secretaría de Desarrollo Urbano y Vivienda (SEDUVI), Procuraduría Ambiental y del Ordenamiento Territorial del Distrito Federal (PAOT), Servicio Geológico Mexicano (SGM) y 
Protección Civil de la alcaldía Álvaro Obregón, realizando el procesamiento de información y análisis con SIG QGIS y GvSIG.

Entrevistas con autoridades a nivel alcaldía, estatal y federal, algunas encargadas de la gestión urbana; permisos de construcción y edificación, atención, corrección o reparación del daño en caso de procesos de remoción en masa o inundación, llevándolos a mapas de riesgo para situaciones reales.

También se realizó búsqueda de información y noticias periodísticas de manera electrónica, para identificar y cartografiar zonas de vulnerabilidad que pudieran presentar procesos de remoción en masa, con mayor intensidad en temporada de lluvias o en momentos de sismicidad, y la relación que existe con la marginación y nivel socioeconómico de las personas afectadas o posibles de ser afectadas.

A continuación, se presentan los datos obtenidos en campo, y la diferencia que existe entre la efectividad del trabajo real cartografiado, evaluado, analizado, supervisado y proyectado en mapas, entre el sistema de información geográfica no gratuito llamado " $X$ " (se tomó esta denominación de " $X$ ", para mantener en el anonimato el nombre de este software por respeto al mismo); y los sistemas de información geográfica gratuitos llamados QGIS y GvSIG, cuya diferencia al parecer de un servidor, es nula, teniendo la misma efectividad, incluso en algunos casos es mejor la de los SIG gratuitos.

\section{Cartografía zona de estudio, con ayuda de Sistemas de Información Geográfica (SIG) gratuitos, QGIS y GvSIG Sistema de Información Geográfica no gratuito " $X$ ", demostrando la misma efectividad}

1. Mapas de crecimiento de la mancha urbana de 1824-2000, Ciudad de México

2. Mapas y cartografía Geomorfológica, Ciudad de México

3. Mapas de población que carece de acceso a servicios básicos por alcaldía, Álvaro Obregón, Ciudad de México

4. Mapas zona de estudio y colonias afectadas por procesos de remoción en masa

5. Mapas de cartografía topográfica (curvas de nivel)

6. Mapas cartografía hidrográfica

7. Mapas zona de riesgo muy alto, zona de estudio

8. Mapas de sombras (Hillshade)

9. Mapas de orientación del terreno

10. Mapas zona urbana vista 3D en plano 2D

11. Imágenes raster y vectores zona de estudio 


\section{Mapas de crecimiento de la mancha urbana de 1824-2000,} Ciudad de México

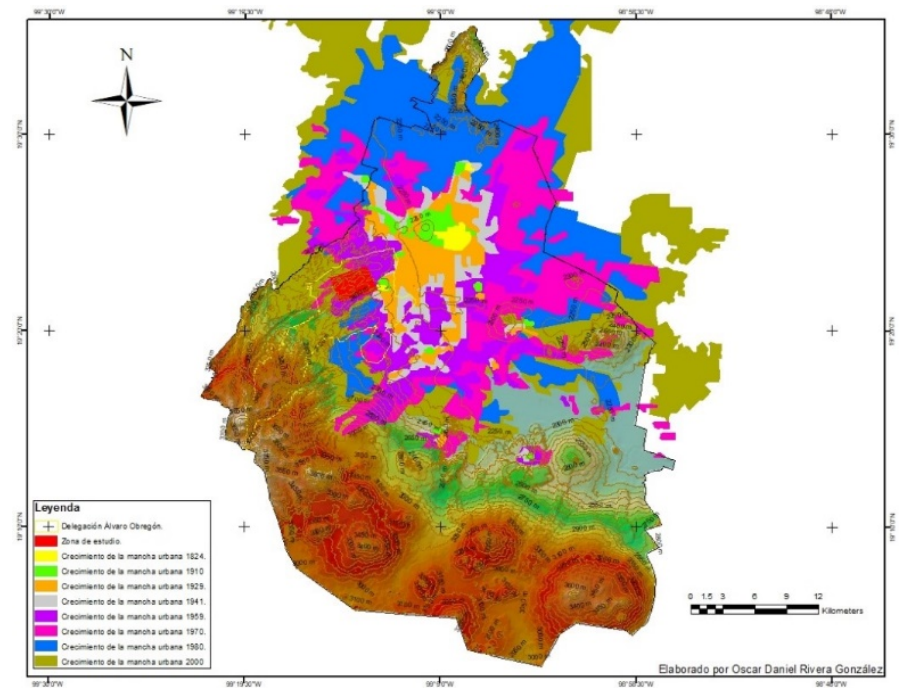

Mapa 1. Elaboración propia con base en censos Instituto Nacional de Estadística y Geografía (INEGI).

Elaborado con Software "X”, Sistema de información Geográfica no gratuito.

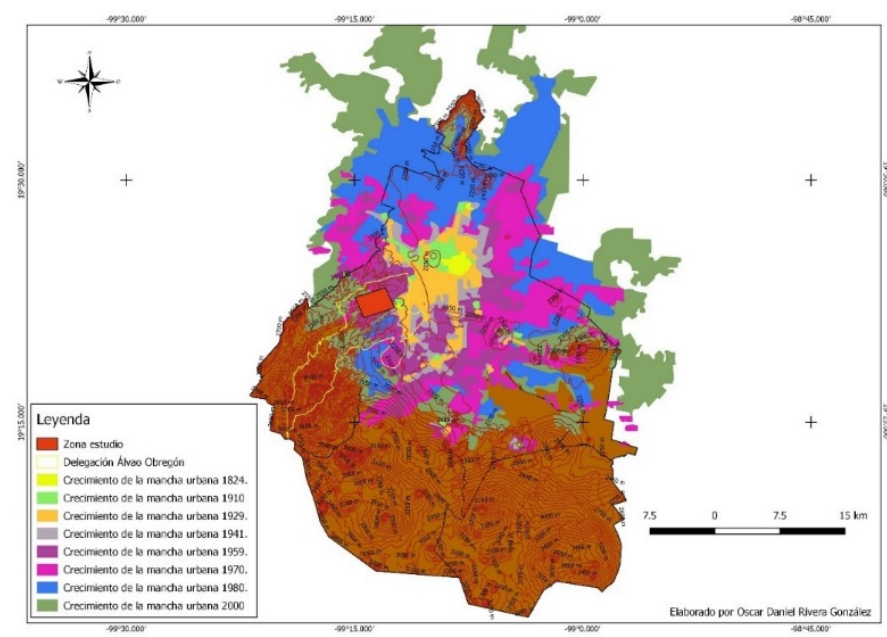

Mapa 2. Elaboración propia con base en censos Instituto Nacional de Estadística y Geografía (INEGI).

Elaborado con Software QGIS, Sistema de información Geográfica gratuito. 


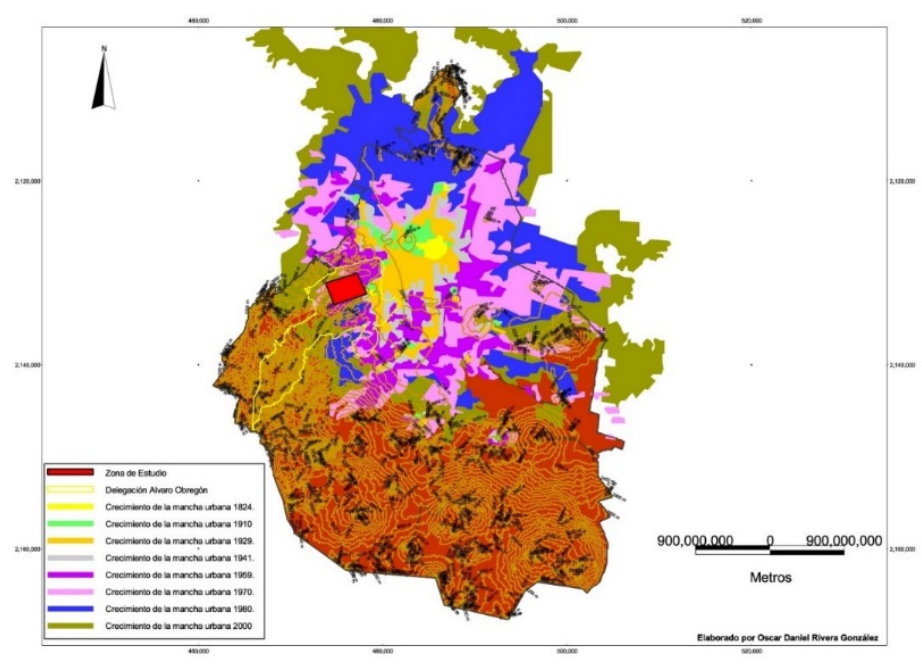

Mapa 3. Elaboración propia con base en censos Instituto Nacional de Estadística y Geografía (INEGI).

Elaborado con Software GvSIG, Sistema de información Geográfica gratuito.

\section{Mapas y cartografía geomorfológica, Ciudad de México, México}

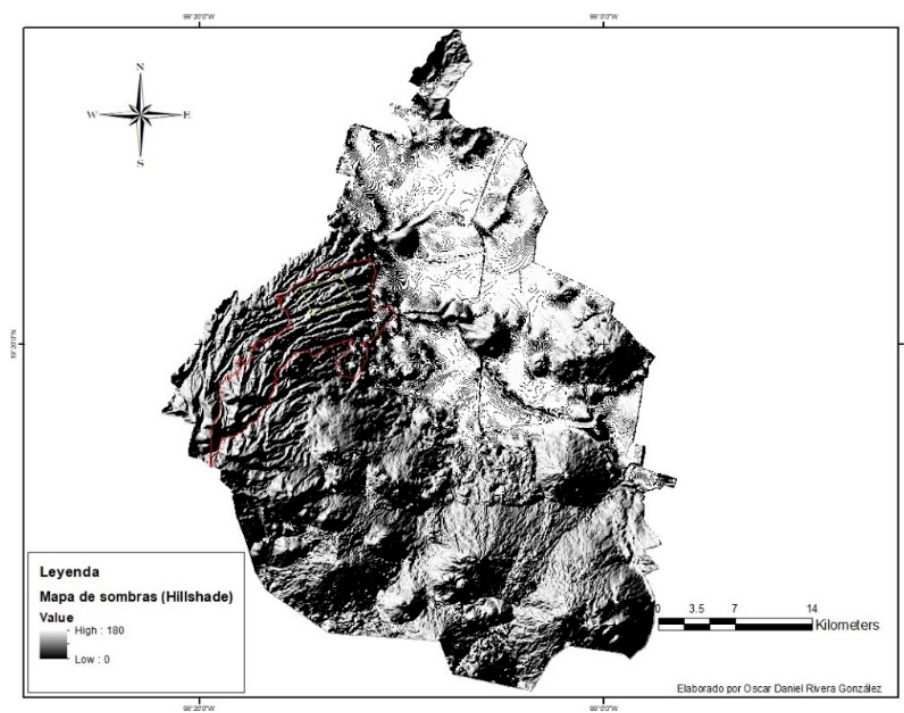

Mapa 4. Elaboración propia con base en datos Raster del Instituto Nacional de Estadística y Geografía (INEGI).

Elaborado con Software "X”, Sistema de información Geográfica no gratuito. 


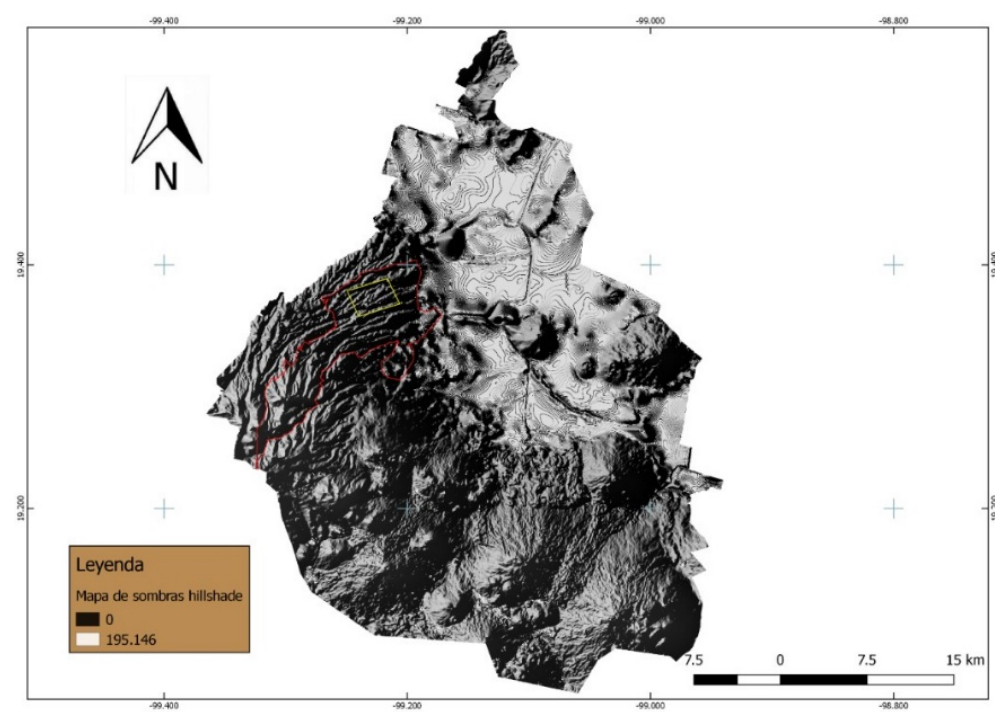

Mapa 5. Elaboración propia con base en datos Raster del Instituto Nacional de Estadística y Geografía (INEGI).

Elaborado con Software QGIS, Sistema de información Geográfica gratuito.

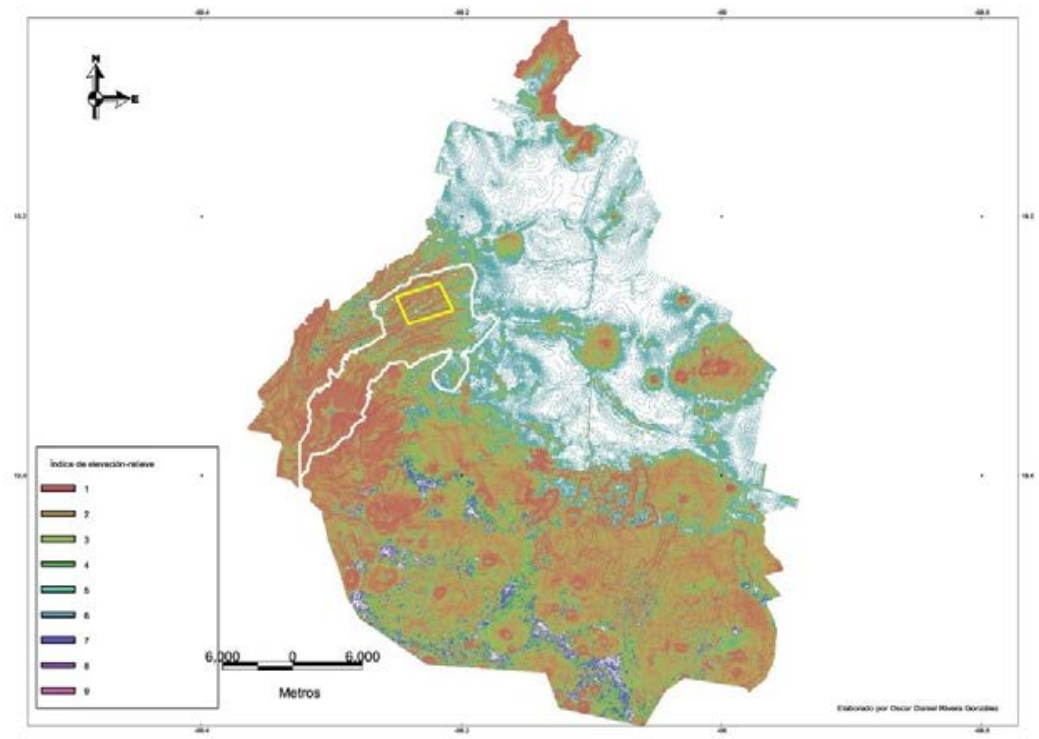

Mapa 6. Elaboración propia con base en datos Raster del Instituto Nacional de Estadística y Geografía (INEGI).

Elaborado con Software GvSIG, Sistema de información Geográfica gratuito. 


\section{Mapas de población que carece de acceso a servicios básicos por alcaldía, Álvaro Obregón, Ciudad de México}

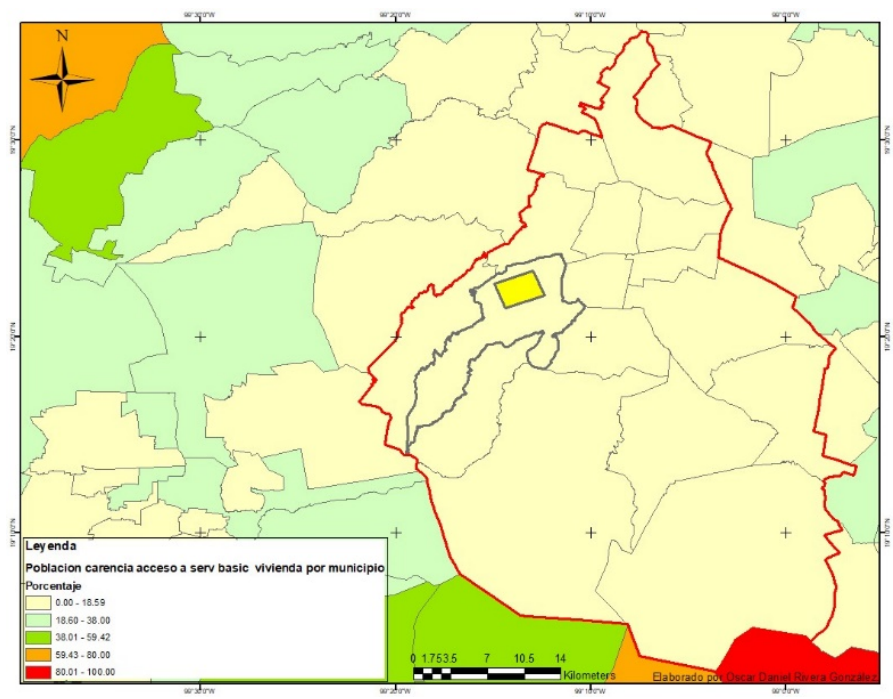

Mapa 7. Elaboración propia con base en datos del Instituto Nacional de Estadística y Geografía (INEGI).

Elaborado con Software “X”, Sistema de información Geográfica no gratuito.

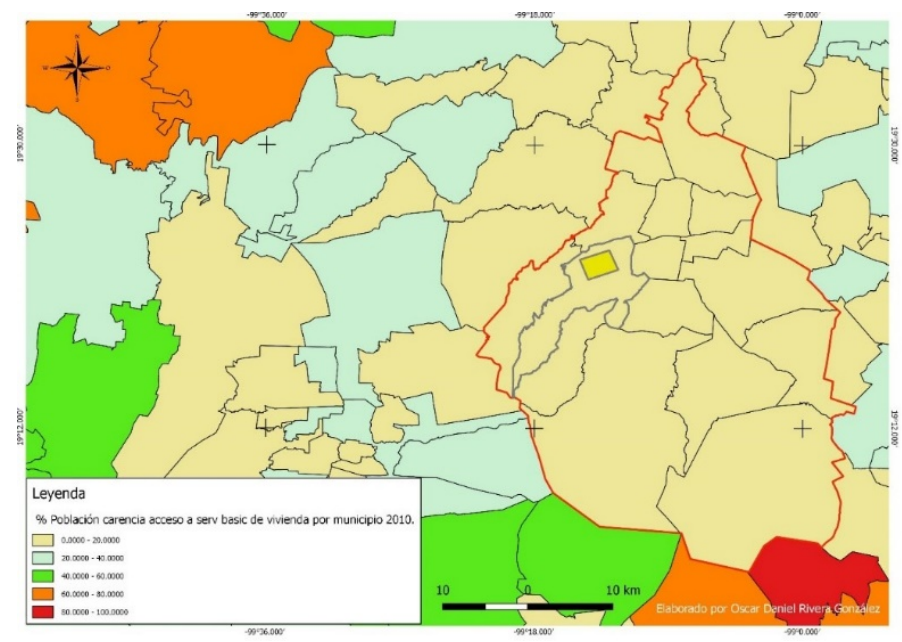

Mapa 8. Elaboración propia con base en datos del Instituto Nacional de Estadística y Geografía (INEGI).

Elaborado con Software QGIS, Sistema de información Geográfica gratuito. 


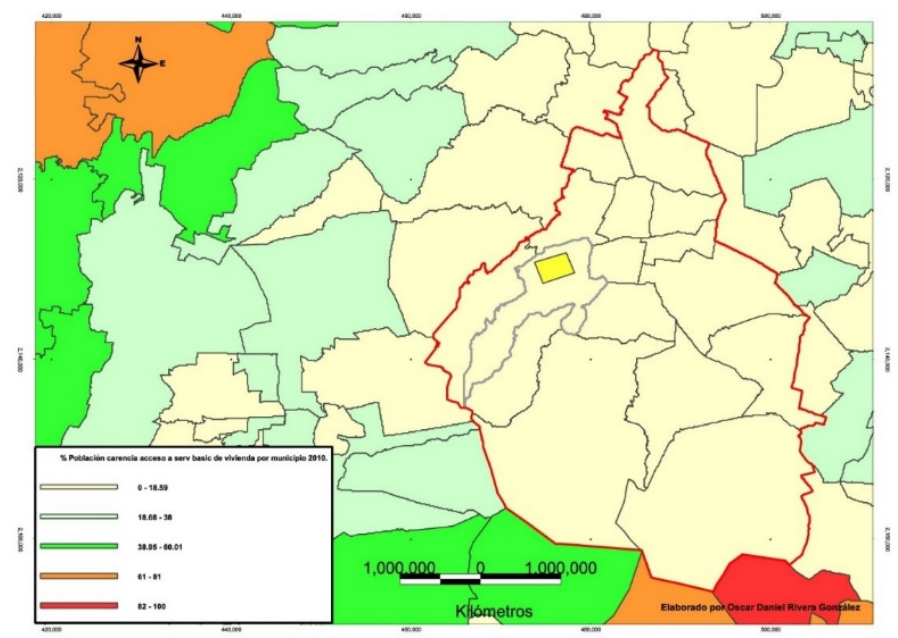

Mapa 9. Elaboración propia con base en datos del Instituto Nacional de Estadística y Geografía (INEGI).

Elaborado con Software GvSIG, Sistema de información Geográfica gratuito.

\section{Mapas zona de estudio y colonias afectadas por procesos de remoción en masa}



Mapa 10. Elaboración propia con base en datos obtenidos de visitas a campo y noticias periodísticas.

Elaborado con Software "X”, Sistema de información Geográfica no gratuito. 


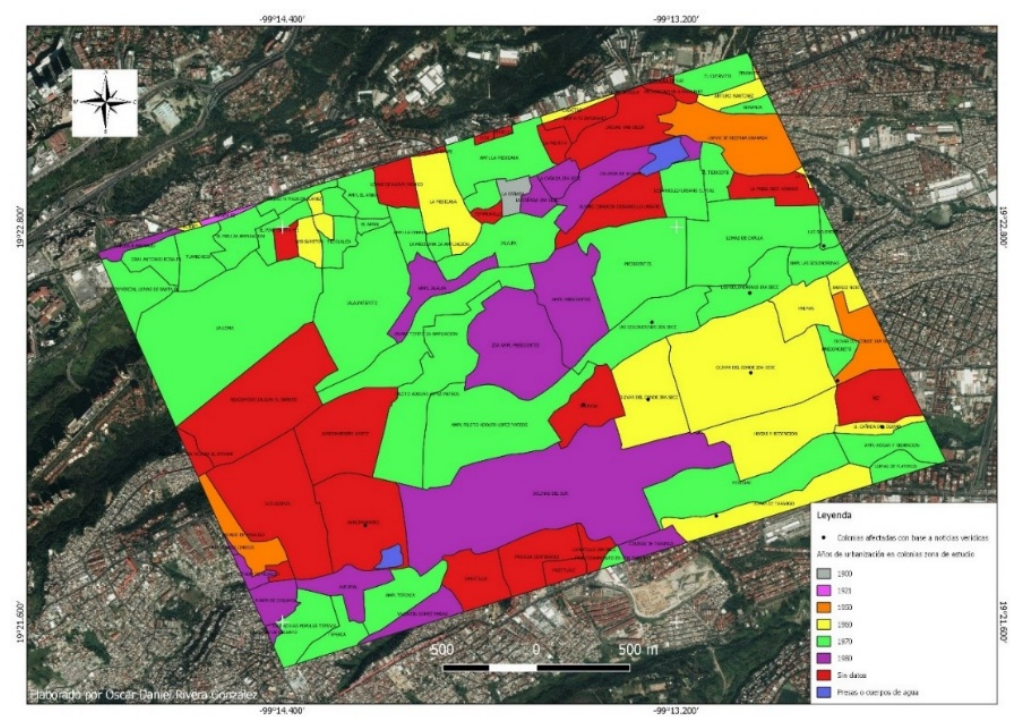

Mapa 11. Elaboración propia con base en datos obtenidos de visitas a campo y noticias periodísticas.

Elaborado con Software QGIS, Sistema de información Geográfica gratuito.

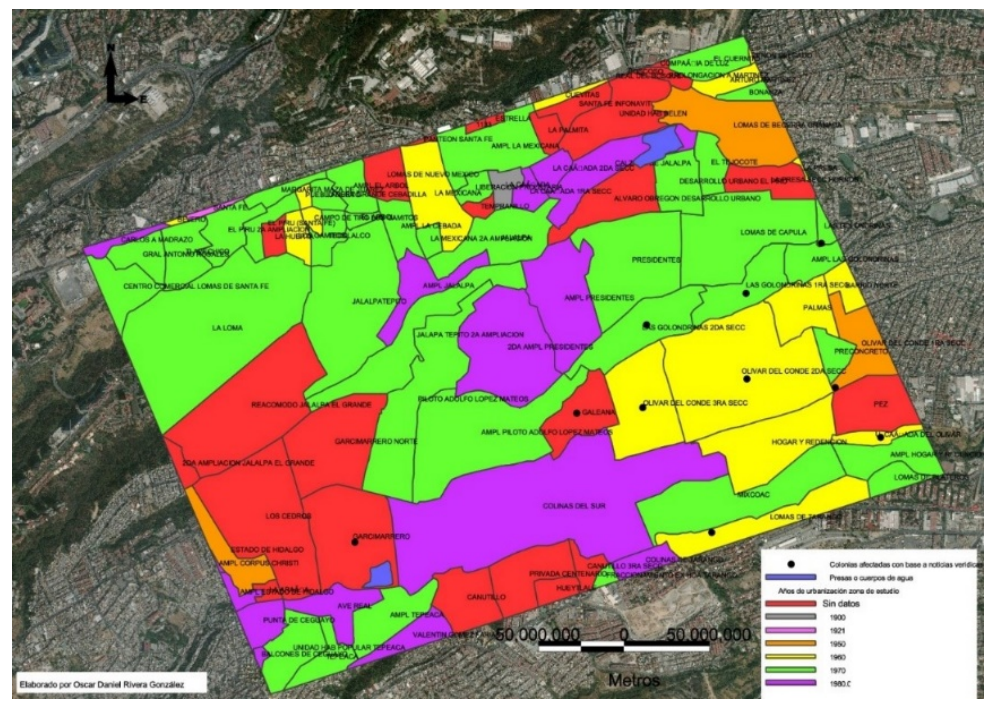

Mapa 12. Elaboración propia con base en datos obtenidos de visitas a campo y noticias periodísticas.

Elaborado con Software GvSIG, Sistema de información Geográfica gratuito. 


\section{Mapas de cartografía topográfica (curvas de nivel)}

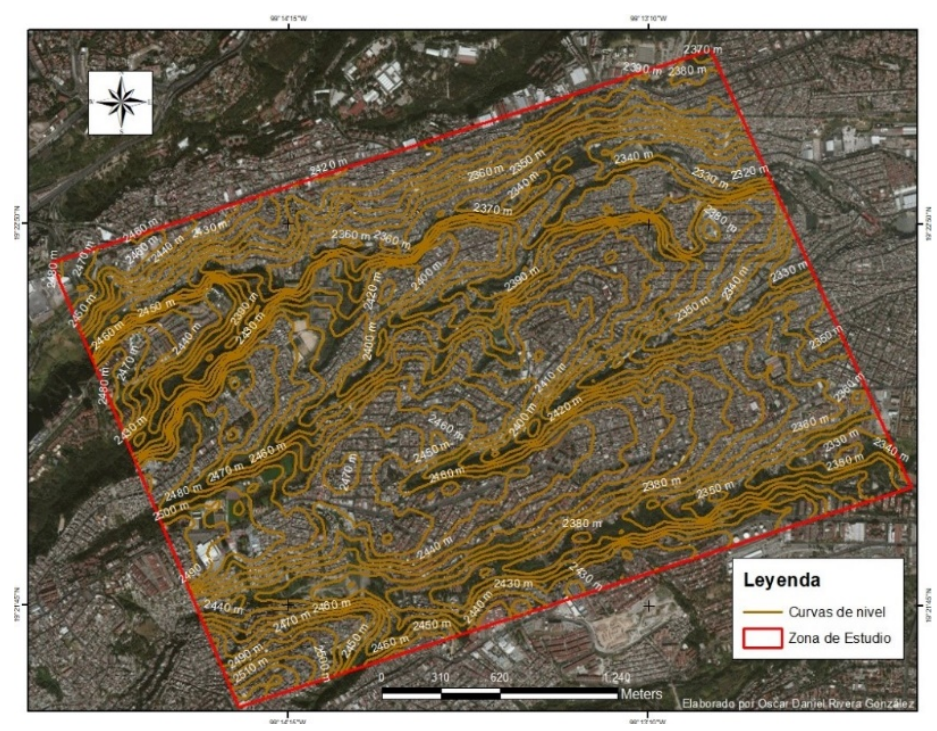

Mapa 13. Elaboración propia con base en datos obtenidos de Modelos de Elevación (MDE) archivos tipo Raster.

Elaborado con Software "X”, Sistema de información Geográfica no gratuito.

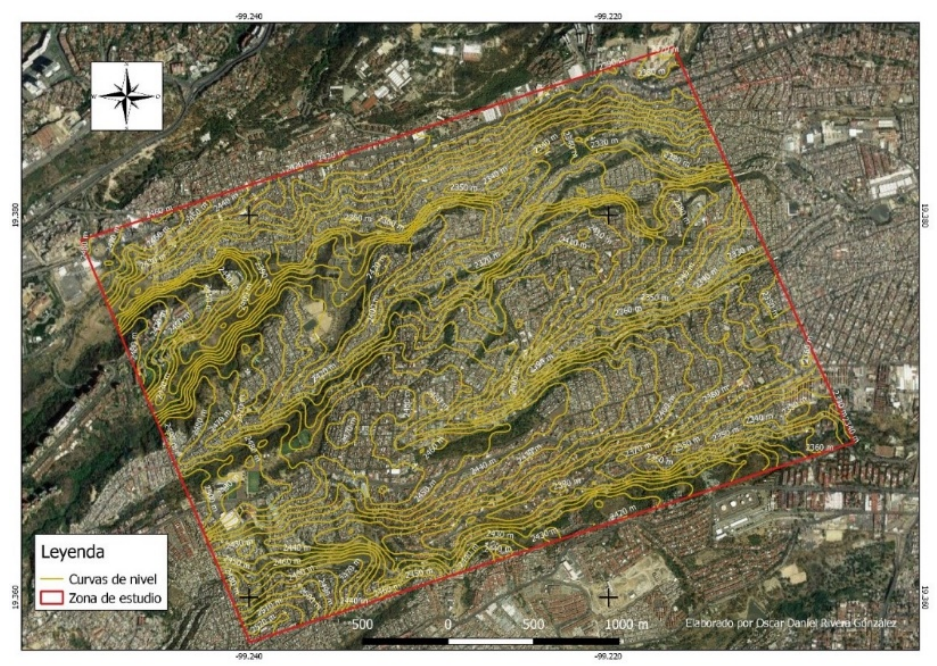

Mapa 14. Elaboración propia con base en datos obtenidos de Modelos de Elevación (MDE) archivos tipo Raster.

Elaborado con Software QGIS, Sistema de información Geográfica gratuito. 


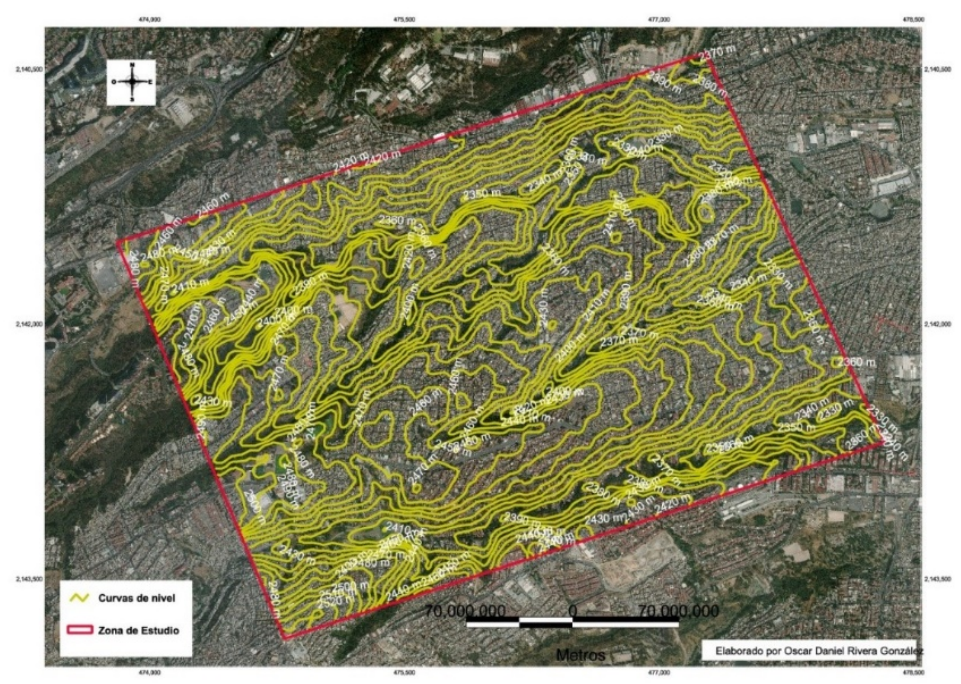

Mapa 15. Elaboración propia con base en datos obtenidos de Modelos de Elevación (MDE) archivos tipo Raster.

Elaborado con Software GvSIG, Sistema de información Geográfica gratuito.

\section{Mapas cartografía hidrográfica}

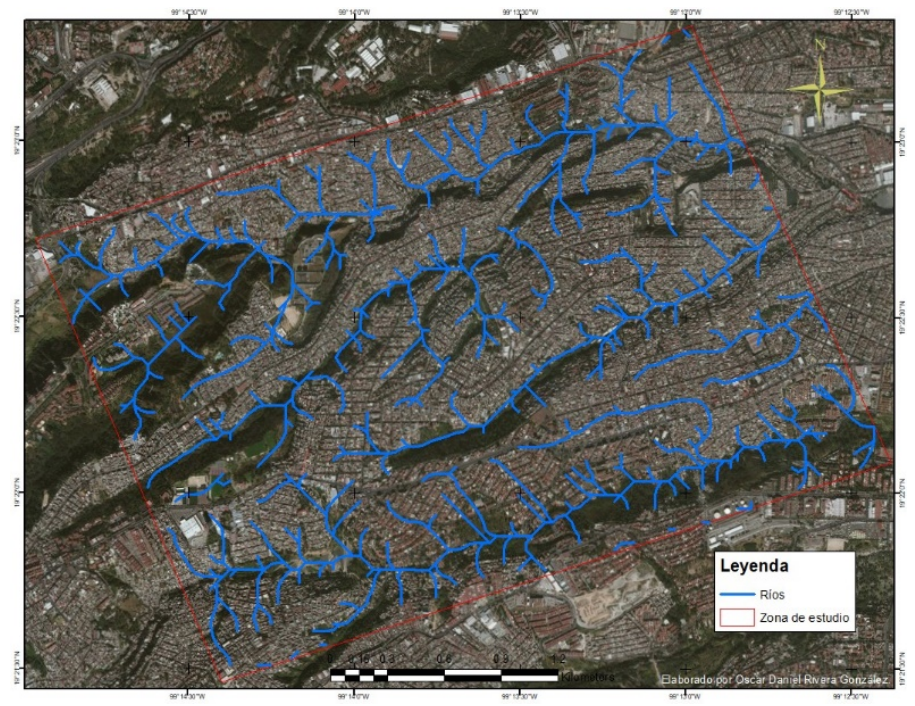

Mapa 16. Elaboración propia con base en datos obtenidos de Modelos de Elevación (MDE) archivos tipo Raster.

Elaborado con Software “X”, Sistema de información Geográfica no gratuito. 


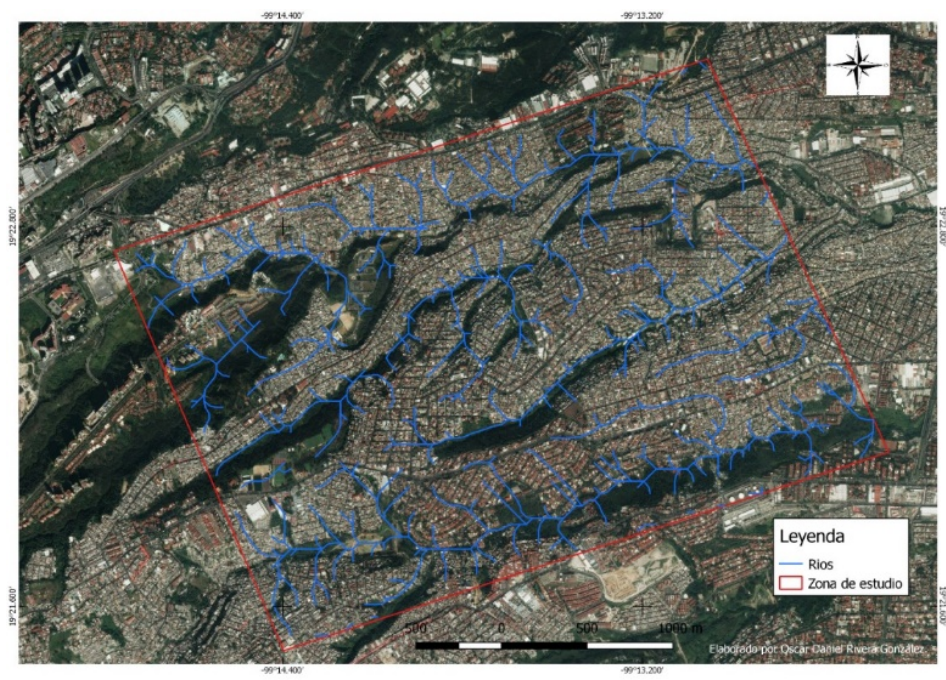

Mapa 17. Elaboración propia con base en datos obtenidos de Modelos de Elevación (MDE) archivos tipo Raster.

Elaborado con Software QGIS, Sistema de información Geográfica gratuito.

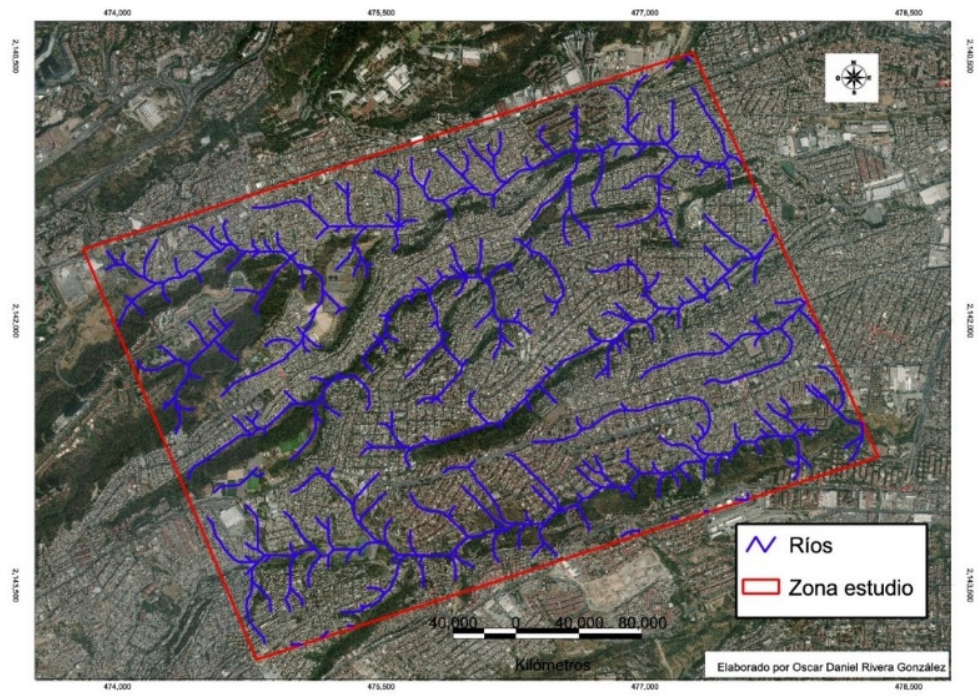

Mapa 18. Elaboración propia con base en datos obtenidos de Modelos de Elevación (MDE) archivos tipo Raster.

Elaborado con Software GvSIG, Sistema de información Geográfica gratuito. 


\section{Mapas zona de riesgo muy alto, zona de estudio}

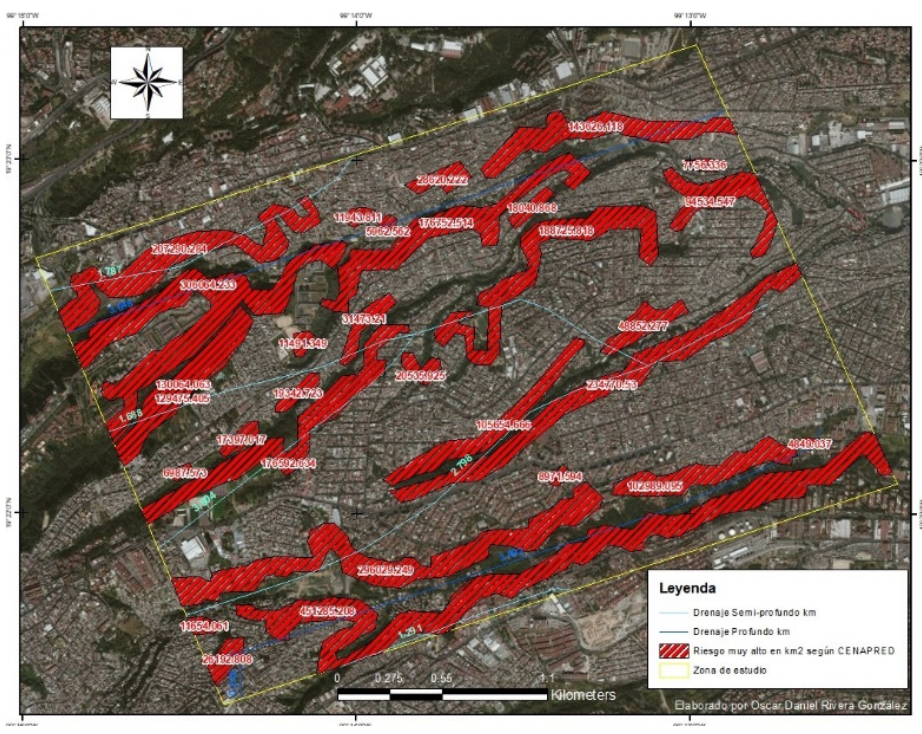

Mapa 19. Elaboración propia con base en datos obtenidos del Centro Nacional de Prevención de Desastres (CENAPRED).

Elaborado con Software "X”, Sistema de información Geográfica no gratuito.

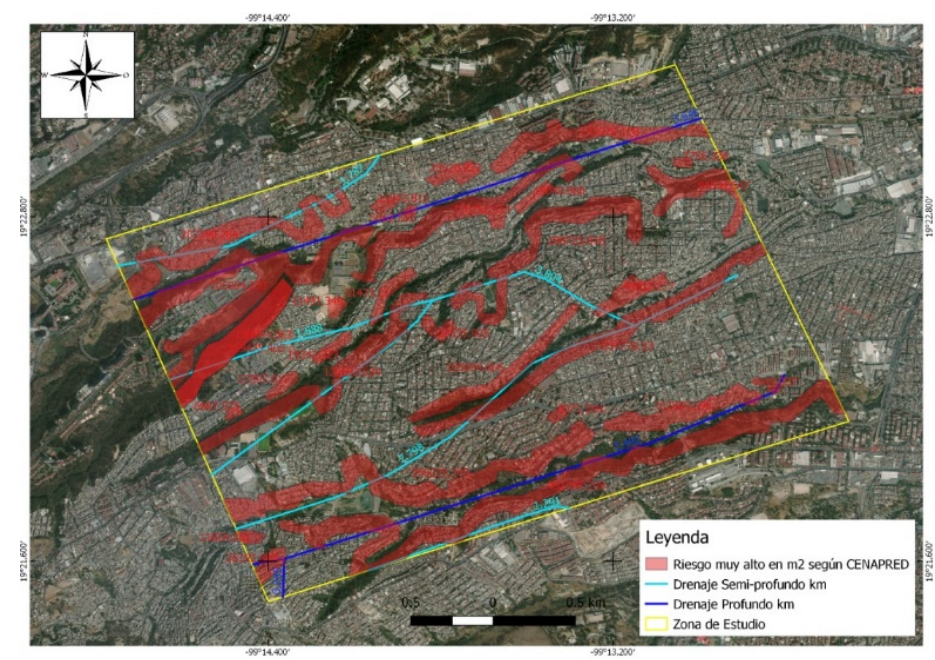

Mapa 20. Elaboración propia con base en datos obtenidos del Centro Nacional de Prevención de Desastres (CENAPRED).

Elaborado con Software QGIS, Sistema de información Geográfica gratuito. 


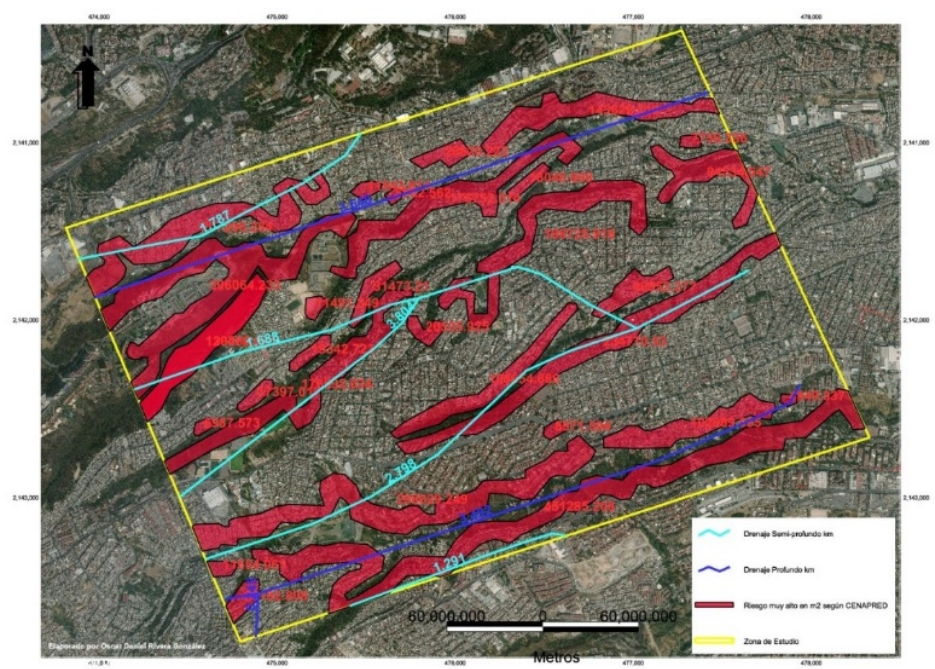

Mapa 21. Elaboración propia con base en datos obtenidos del Centro Nacional de Prevención de Desastres (CENAPRED).

Elaborado con Software GvSIG, Sistema de información Geográfica gratuito.

\section{Mapas de sombras (Hillshade)}

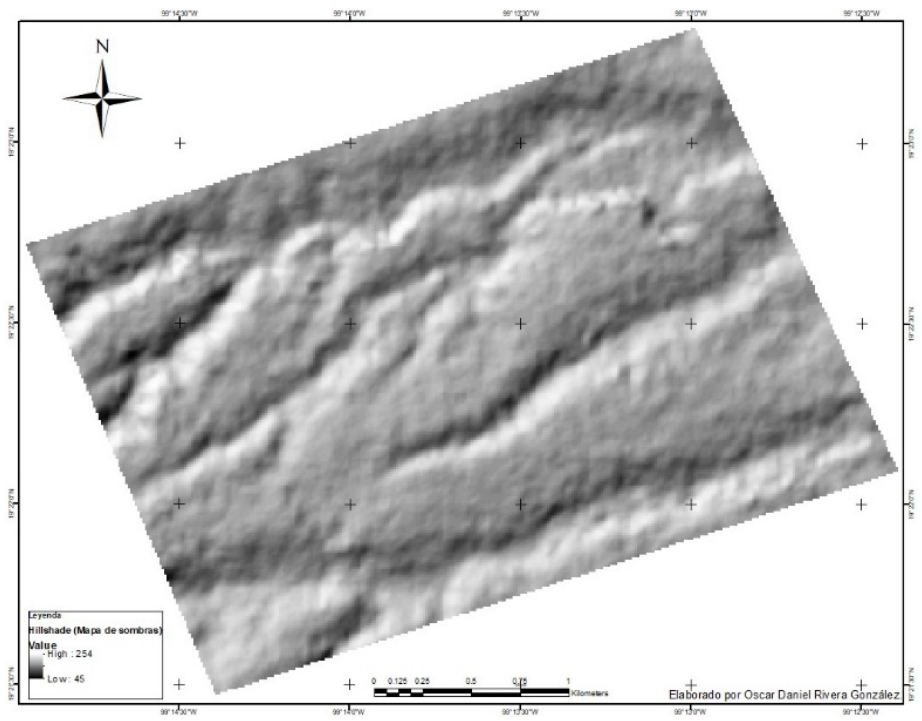

Mapa 22. Elaboración propia con base en datos obtenidos de Modelos de Elevación (MDE) archivos tipo Raster.

Elaborado con Software “X”, Sistema de información Geográfica no gratuito. 


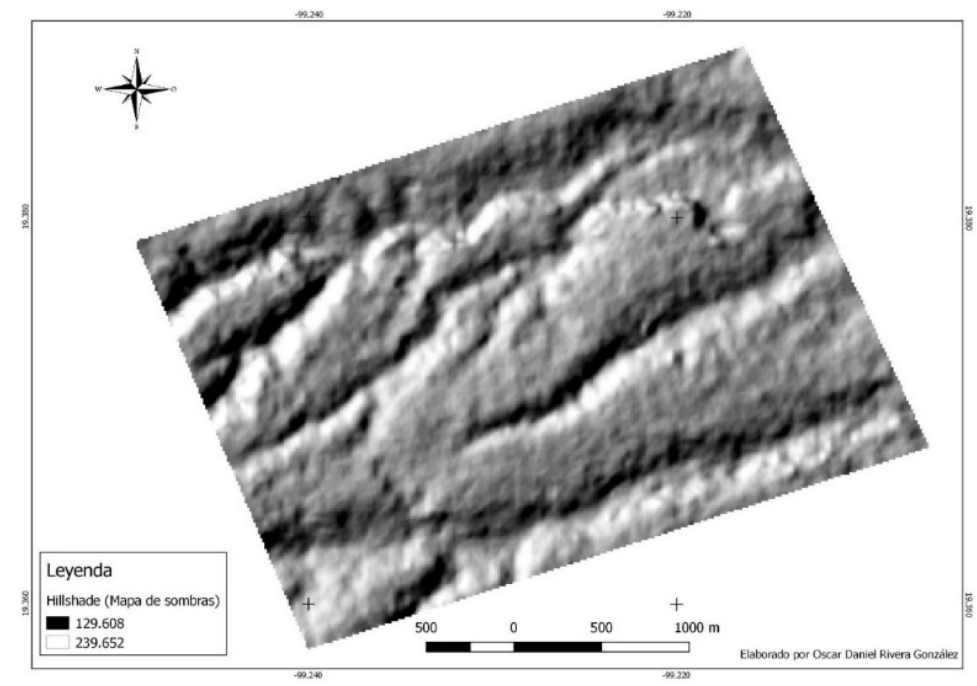

Mapa 23. Elaboración propia con base en datos obtenidos de Modelos de Elevación (MDE) archivos tipo Raster.

Elaborado con Software QGIS, Sistema de información Geográfica gratuito.

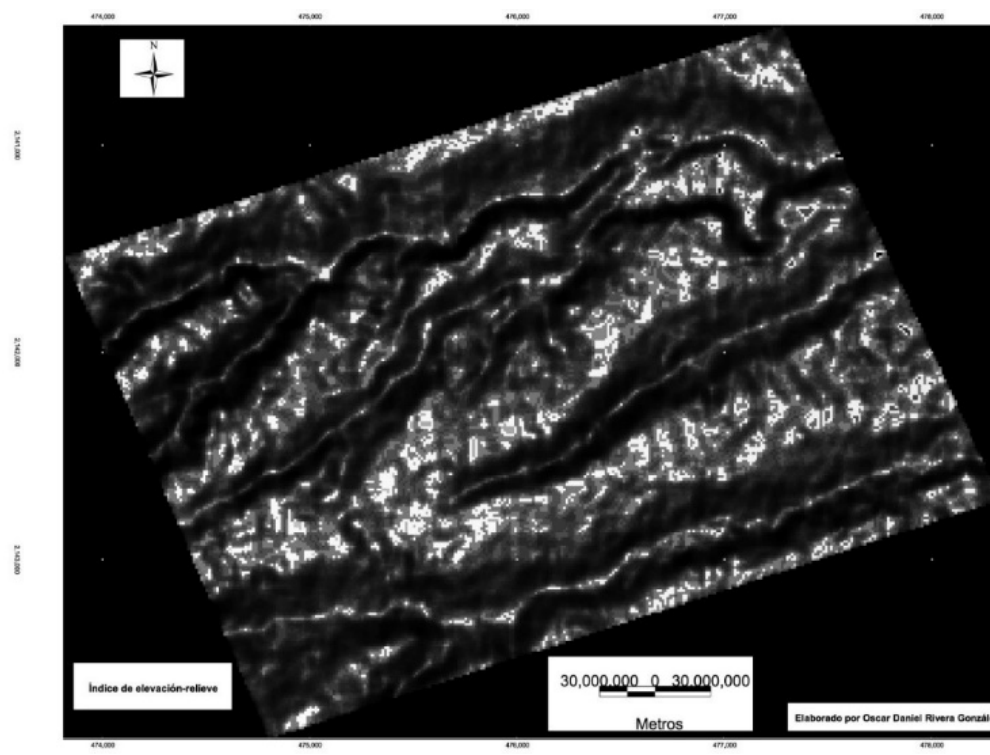

Mapa 24. Elaboración propia con base en datos obtenidos de Modelos de Elevación (MDE) archivos tipo Raster.

Elaborado con Software GvSIG, Sistema de información Geográfica gratuito. 


\section{Mapas de orientación del terreno}

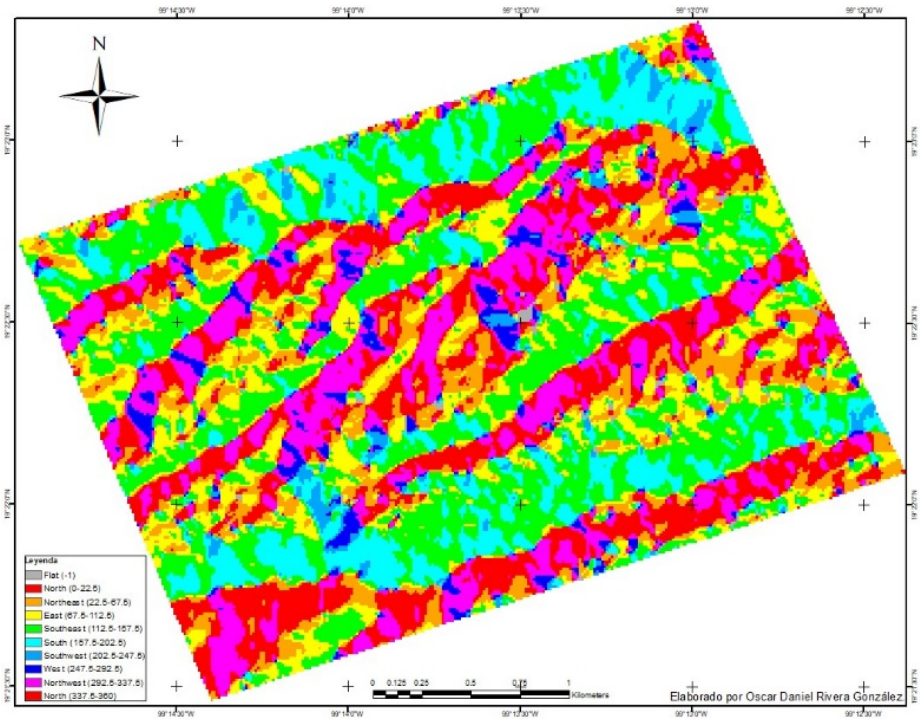

Mapa 25. Elaboración propia con base en datos obtenidos de Modelos de Elevación (MDE) archivos tipo Raster.

Elaborado con Software "X”, Sistema de información Geográfica no gratuito.

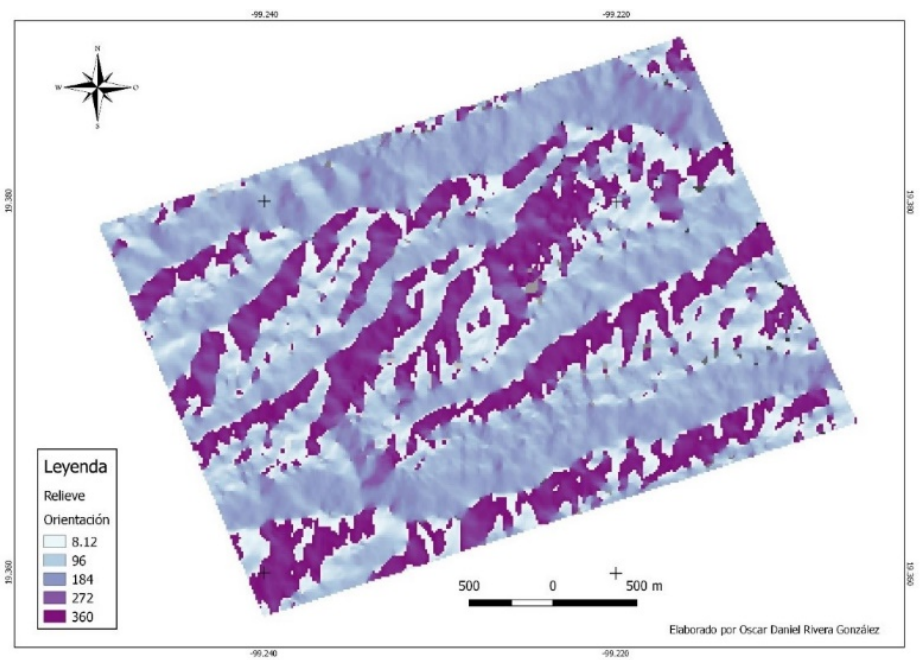

Mapa 26. Elaboración propia con base en datos obtenidos de Modelos de Elevación (MDE) archivos tipo Raster.

Elaborado con Software QGIS, Sistema de información Geográfica gratuito. 


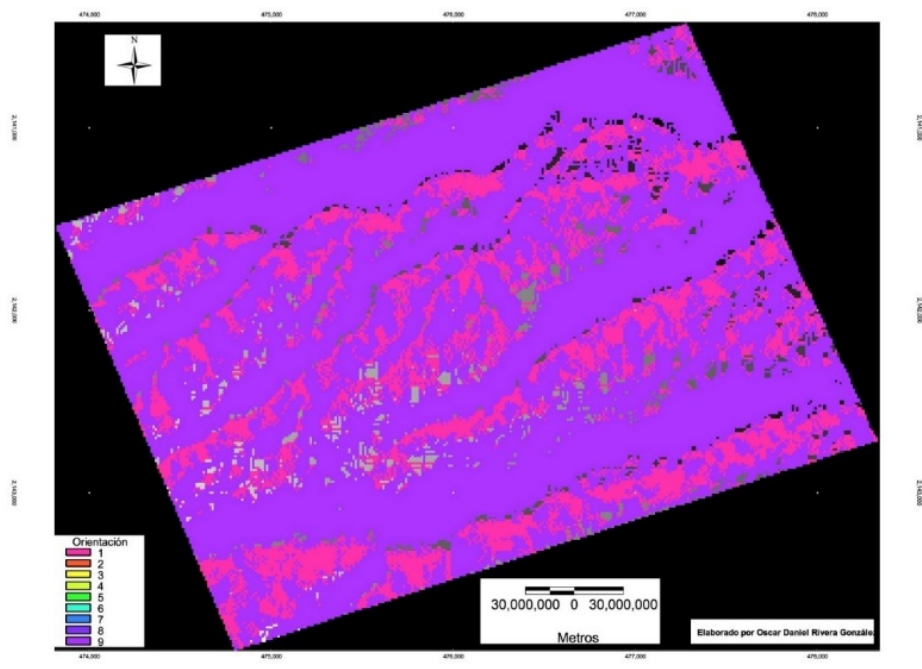

Mapa 27. Elaboración propia con base en datos obtenidos de Modelos de Elevación (MDE) archivos tipo Raster.

Elaborado con Software GvSIG, Sistema de información Geográfica gratuito.

\section{Mapas zona urbana vista 3D en plano 2D}

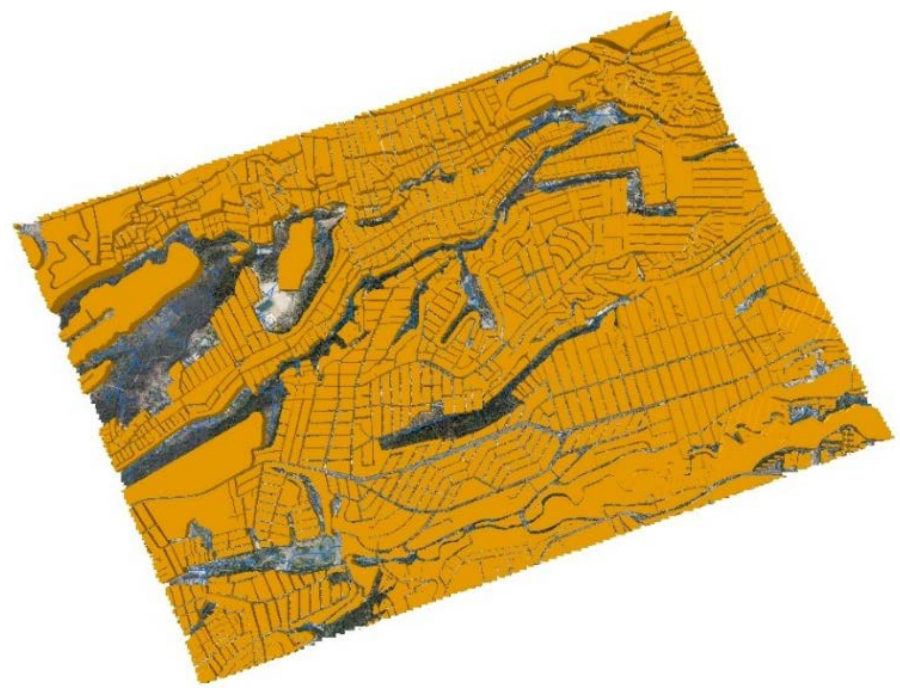

Mapa 28. Elaboración propia con base en datos obtenidos de visitas en campo a la zona de estudio.

Elaborado con Software “X”, Sistema de información Geográfica no gratuito. 


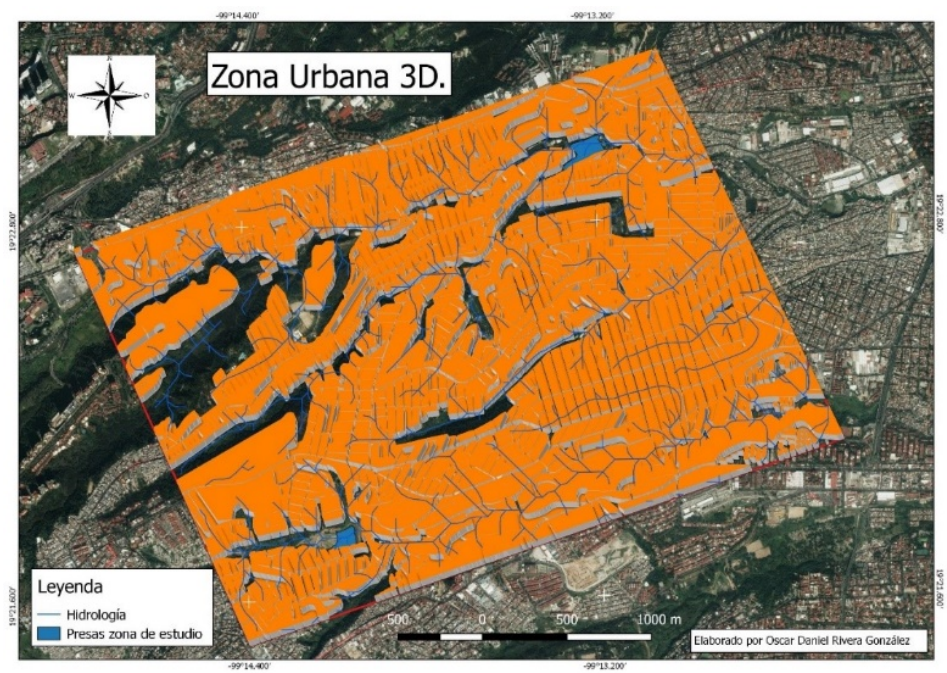

Mapa 29. Elaboración propia con base en datos obtenidos de visitas en campo a la zona de estudio.

Elaborado con Software QGIS, Sistema de información Geográfica gratuito.

\section{Imágenes raster y vectores zona de estudio}

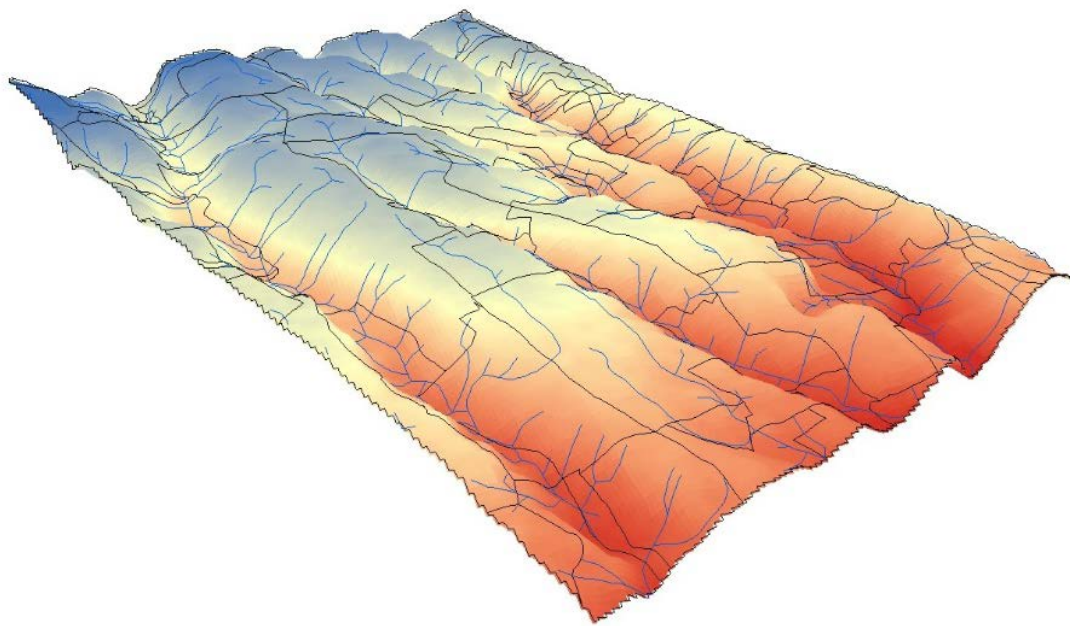

Imagen 1. Elaboración propia, Modelo digital de elevación vista 3D, zona de estudio. Elaborado con Software "X”, Sistema de información Geográfica no gratuito. 


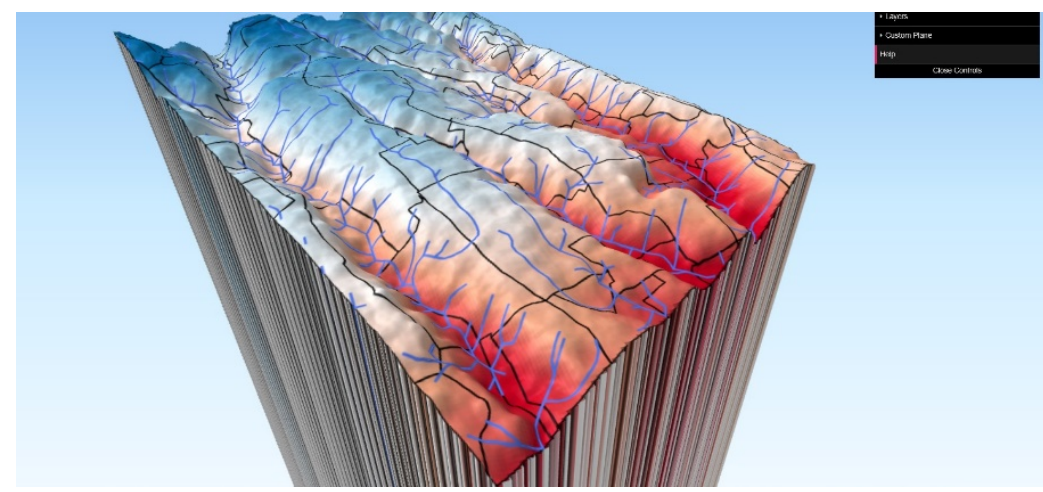

Imagen 2. Elaboración propia, Modelo digital de elevación vista 3D, zona de estudio. Elaborado con Software QGIS, Sistema de información Geográfica gratuito.

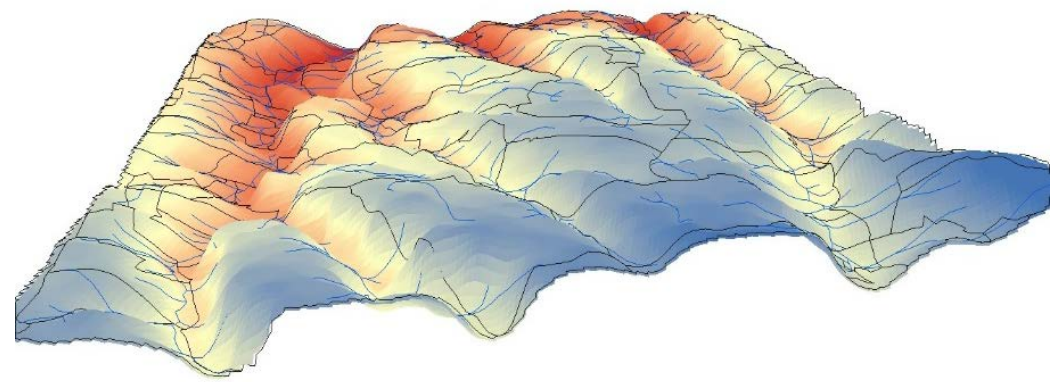

Imagen 3. Elaboración propia, Modelo digital de elevación vista 3D, zona de estudio. Elaborado con Software "X”, Sistema de información Geográfica no gratuito.

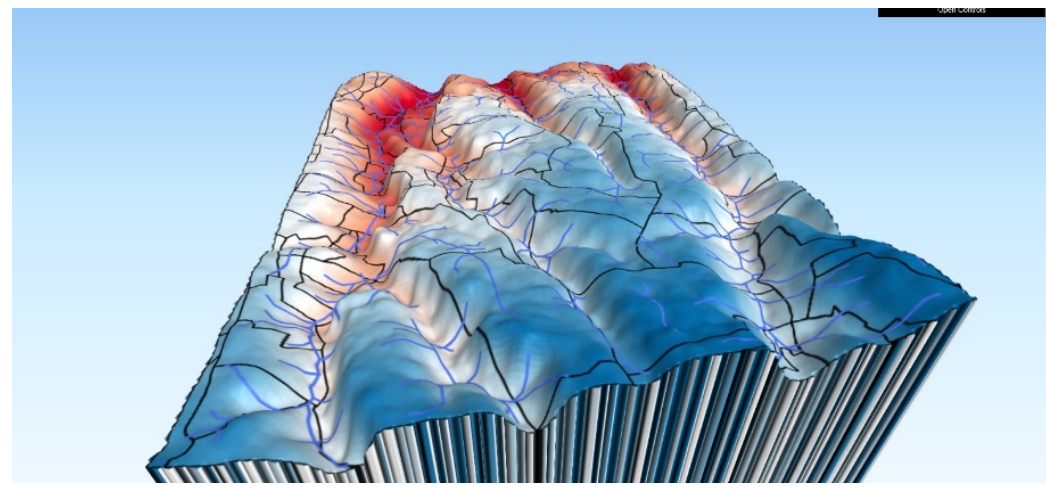

Imagen 4. Elaboración propia, Modelo digital de elevación vista 3D, zona de estudio. Elaborado con Software QGIS, Sistema de información Geográfica gratuito. 


\section{Conclusiones}

La elaboración de cartografía nueva, reciente, actual, innovadora y original, demuestra que los softwares gratuitos en general y poniendo como ejemplo a QGIS y GVSIG, con respecto de los SIG no gratuitos, sin duda tienen la misma efectividad y nivel de detalle, el uso de softwares de SIG gratuitos, tienen la misma efectividad pues compiten entre ellos, por lo que pudiéramos mencionar que son complementarios, es de esperar a que en un futuro su auge sea mayor, para que todo tipo de estudiante independientemente del nivel educativo y estrato socioeconómico que se encuentre, lo pueda utilizar, inclusive en la actualidad, algunas escuelas y empresas en México privadas y de gobierno utilizan SIG no gratuitos, las cuales seguramente cambiarán a la utilización de SIG gratuitos y así no pagar lujos innecesarios.

Una recomendación particular es que se migre a los SIG gratuitos, ya que su utilidad es muy confiable hablando de mapas vectoriales, modelos raster, elaboración de nueva cartografía, archivos KML y KMZ, análisis del terreno, reproyecciones, mediciones reales en el terreno, pluglins nuevos y sin costo, herramientas de geoprosesamiento, QuickMap Services, perfiles de terreno, topología, geomorfometría, análisis del relieve, en pocas palabras, los SIG gratuitos tienen todo lo que un estudiante de nivel básico, medio o superior de todos los estratos socioeconómicos, profesionista o investigador, buscan para resolver muchas problemáticas dadas en el planeta Tierra y llevarlas a cabo en la enseñanza o en la aplicación en la vida real y proyectarlas en la cartografía.

\section{Agradecimientos}

A la Universidad Nacional Autónoma de México, a Valeria Liliana González Gallegos, a Cecilia San Agustín Cristóbal y al doctor Eduardo Reinoso Angulo.

\section{Referencias}

Centro Nacional de Prevención de Desastres (CENAPRED). https://www.gob.mx/cenapred Comisión Nacional para el Conocimiento y Uso de la Biodiversidad (CONABIO). https://www.gob.mx/conabio

Comisión Nacional de Áreas Naturales Protegidas (CONANP). https://www.gob.mx/conanp Cuanalo, O. (2016). Fenómenos de remoción en masa. Acciones para reducir la vulnerabilidad y el riesgo, (pp. 28-45). Editorial Vector, México.

Fariña, J. (2013). Manual de Diseño Bioclimático Urbano, (pp. 46-69). Editorial Instituto Politécnico de Bragança, Portugal.

Harvey, D., (2003). Espacios del Capital, (pp. 360-373). Editorial Akal, España, Madrid. Instituto Nacional de Estadística y Geografía (INEGI). https://www.inegi.org.mx/ Jane J., (2011). Muerte y vida de las grandes ciudades, pp. 33-49. Editorial Capitán Swing, España. 
Lugo J. (2005). Los procesos de remoción en masa en la Sierra Norte de Puebla, octubre de 1999: causa y efectos. Revista Mexicana de Ciencias Geológicas, 22(2), 212-218.

Procuraduría Ambiental y del Ordenamiento Territorial del Distrito Federal (РAOT). http://www.paot.org.mx/

Protección Civil de la alcaldía Álvaro Obregón. http://www.aao.gob.mx/

Renda E. (2017). Manual para la elaboración de mapas de riesgo, (pp. 43-59). Editorial Programa Naciones Unidas para el Desarrollo (PNUD), Argentina.

Secretaría de Desarrollo Urbano y Vivienda (SEDUVI). https://www.seduvi.cdmx.gob.mx/

Secretaría de Medio Ambiente (SEDEMA). https://www.sedema.cdmx.gob.mx/

Servicio Geológico Mexicano (sGM). https://www.gob.mx/sgm

Servicio Meteorológico Nacional (sMN). https://smn.conagua.gob.mx/es/

\section{Instituciones gubernamentales y privadas, leyes, reglamentos, normas, estatutos consultados}

Ley General de Asentamientos Humanos, Nueva Ley publicada en el Diario Oficial de la Federación, 21 de julio de 1993, texto vigente, última reforma publicada DOF 30-11-2010.

Ley General de Protección Civil, 2000; Ley General de Asentamientos Humanos, Ley General del Equilibrio Ecológico y la Protección al Ambiente, Ley de Aguas Nacionales, Ley Forestal, Ley General de Salud, Reglamentos de Construcción.

Prevención y atención de desastres en México, Ma. Lorena Alpízar Marín.

\section{Softwares utilizados}

SIG QGIS.

GvSIG. 